\title{
A fresh look at the role of spiramycin in preventing a neglected disease: meta-analyses of observational studies
}

\author{
Jose G. Montoya ${ }^{1}$, Katherine Laessig ${ }^{2}$, Mir Sohail Fazeli ${ }^{3 *}$ (D) Gaye Siliman ${ }^{4}$, Sophie S. Yoon ${ }^{4}$, \\ Elizabeth Drake-Shanahan ${ }^{5}$, Chengyue Zhu ${ }^{5}$, Akbar Akbary ${ }^{5}$ and Rima McLeod ${ }^{6^{*}}$
}

\begin{abstract}
Purpose: We aimed to investigate the effect of antepartum treatment with spiramycin with or without subsequent pyrimethamine-sulfonamide-folinic acid, compared to no treatment, on the rate of mother-to-child transmission (MTCT) of Toxoplasma gondii (T. gondii) and incidence/severity of sequelae in the offspring.

Methods: Embase and PubMed were searched for literature on spiramycin in pregnant women suspected/diagnosed with T. gondii infection. Meta-analyses were performed using random-effects model.

Results: Thirty-three studies (32 cohorts and 1 cross-sectional study), with a total of 15,406 mothers and 15,250 offspring, were pooled for analyses. The MTCT rate for all treated patients was significantly lower than the untreated [19.5\% (95\% Cl 14-25.5\%) versus 50.7\% (95\% Cl 31.2-70\%), $p<0.001]$. The transmission rate in patients on spiramycin monotherapy was also significantly lower than untreated [17.6\% (95\% Cl 9.9-26.8\%) versus $50.7 \%(95 \% \mathrm{Cl} 31.2-70 \%)$, $p<0.001]$.

Conclusion: Results indicate significant reduction in MTCT rates following spiramycin treatment of suspected/diagnosed maternal T. gondii infection.
\end{abstract}

Keywords: Spiramycin, Toxoplasmosis, Systemic protozoa, Sequelae, Mortality, Transmission

\section{Introduction}

Toxoplasmosis is a parasitic disease caused by Toxoplasma gondii ( $T$. gondii). It is a neglected disease in some regions of the globe with emerging knowledge and new approaches arising for its diagnosis and treatment. Acute T. gondii infection acquired during pregnancy presents a serious risk for potential mother-to-child transmission (MTCT). Fetal infection with T. gondii can lead to

\footnotetext{
*Correspondence: mfazeli@evidinno.com; rmcleod@uchicago.edu

${ }^{3}$ Evidinno Outcomes Research Inc, Vancouver, Canada

${ }^{6}$ Division of Biologic Sciences, Departments of Pediatrics (Infectious

Diseases) and Ophthalmology and Visual Sciences, University of Chicago, Chicago, IL, USA

Full list of author information is available at the end of the article
}

spontaneous abortion, stillbirth, or serious/severe postnatal sequelae [1-3].

After diagnosis, treatment is often recommended to prevent MTCT $[4,5]$. Spiramycin (a macrolide antibiotic) is prescribed when primary maternal infection is diagnosed during gestation in an attempt to prevent MTCT $[6,7]$. Spiramycin is not approved in the United States (U.S.), but is accessible through a compassionate use program for toxoplasmosis during pregnancy [8]. The burden of congenital toxoplasmosis may be disproportionately borne by patients of lower socioeconomic strata, and those who lack access to antepartum screening and prevention. However, in the U.S. infection acquired in gestation that places the fetus at risk for congenital infection affects persons of all demographics. original author(s) and the source, provide a link to the Creative Commons licence, and indicate if changes were made. The images or other third party material in this article are included in the article's Creative Commons licence, unless indicated otherwise in a credit line to the material. If material is not included in the article's Creative Commons licence and your intended use is not permitted by statutory regulation or exceeds the permitted use, you will need to obtain permission directly from the copyright holder. To view a copy of this licence, visit http://creativecommons.org/licenses/by/4.0/. The Creative Commons Public Domain Dedication waiver (http://creativeco mmons.org/publicdomain/zero/1.0/) applies to the data made available in this article, unless otherwise stated in a credit line to the data. 
Timing of administration of spiramycin as the initial treatment when primary infection with $T$. gondii occurs during gestation varies by center, depending on when the diagnosis is made between 16 to 32 weeks of gestation (WG) [9-11]. After 14-18 WG and before any fetal infection is documented/diagnosed, additional treatment options include: (a) continuation of spiramycin monotherapy; (b) switching to combination therapy with pyrimethamine-sulfonamide-folinic acid (PSF); (c) PSF alternating or in combination with spiramycin, and/ or (d) other experimental treatments that are not standard of care [12]. However, if fetal infection is suspected (based on fetal ultrasound findings suggestive of congenital toxoplasmosis $[\mathrm{CT}]$ ) or confirmed (with presence of Toxoplasma DNA in amniotic fluid by polymerase chain reaction testing), PSF is instituted or continued throughout gestation and the infant's first year of life [12].

Although the reported effectiveness of spiramycin as antepartum treatment is currently generally accepted, no recent meta-analysis has assessed the efficacy of spiramycin use. Furthermore, reports published between 1999 and 2006 [13-18] cast doubt on the effectiveness of spiramycin, leading a group of investigators to call for randomized placebo-controlled clinical trials $[13,18]$ and others to advocate for the discontinuation of systematic antepartum screening and treatment programs $[19,20]$. During this period of time, diagnosing or treating congenital toxoplasmosis at all was controversial in some settings. Thus, especially in light of the recent global initiatives to prevent this infection it is critical to evaluate the evidence for the efficacy and role of spiramycin.

To address differences in approach concerning prenatal screening, treatment, and the use of spiramycin, we conducted meta-analyses of literature published as of August 2017 to investigate the effect of antepartum treatment with spiramycin monotherapy or spiramycin combined/ alternated with PSF compared to no treatment on the rate of MTCT and the incidence/severity of sequelae in the offspring.

\section{Materials and methods}

\section{Literature search and study selection}

A focused search on the treatment of T. gondii infection during pregnancy was conducted on Embase and PubMed using keywords: "Spiramycin AND Pregnancy" and "Spiramycin AND Toxoplasmosis". The search results and citation lists of eligible publications were reviewed for inclusion. Studies that were not published in English; did not report on MTCT rate or sequelae; compared various diagnostic methods; or focused on etiology, pathology, pathogenesis, or epidemiology of toxoplasmosis were excluded. Results were reported according to the Preferred Reporting Items for Systematic Reviews and MetaAnalyses (PRISMA) guidelines [21].

\section{Data configuration}

Data were extracted by investigators and entered into Doctor Evidence LLC's DOC Data version 2.0 software platform. The primary outcome was MTCT rate, and secondary outcomes were incidence/severity of sequelae in infected fetuses/infants. Sequelae were defined based on previous studies [22, 23]. Definition of outcomes and denominators are provided in Table 1 and Additional file 1: Tables S1, S2. The Newcastle-Ottawa Scale [24] was used to assess the quality of the included observational studies (detailed in Additional file 1: Table S4).

\section{Statistical analyses \\ Meta-analyses}

Meta-analyses were conducted to determine pooled estimates. Outcomes were pooled based on availability across the included studies. Analyses were performed for the following treatment groups: untreated, spiramycin monotherapy, and spiramycin monotherapy or spiramycin monotherapy followed by spiramycin in combination or alternating with PSF, heretofore referred to as "spiramycin and/or PSF".

A random-effects model by DerSimonian and Laird 1986 [25] was used to derive composite odds ratio of

Table 1 Outcome definitions

\begin{tabular}{|c|c|c|}
\hline Outcome & Definition & Denominators \\
\hline Mother-to-child transmission (MTCT) & Transmission of Toxoplasma gondii from mother-to-child & All infected mothers \\
\hline $\begin{array}{l}\text { Mortality (pre- and post-natal) excluding elective } \\
\text { terminations }^{\mathrm{a}}\end{array}$ & $\begin{array}{l}\text { Includes toxoplasmosis-associated spontaneous abortions, } \\
\text { stillbirths, and postnatal infant deaths }\end{array}$ & All infected fetuses/children \\
\hline $\begin{array}{l}\text { All serious/severe sequelae and all mortality (pre- and } \\
\text { post-natal) }\end{array}$ & $\begin{array}{l}\text { Includes serious/severe sequelae and all mortality (all } \\
\text { toxoplasmosis-associated terminations, miscarriages, still- } \\
\text { births, and infant deaths within the first year of life) }\end{array}$ & $\begin{array}{l}\text { All infected mothers } \\
\text { All infected fetuses/children }\end{array}$ \\
\hline $\begin{array}{l}\text { All mild/moderate/severe sequelae and infant mortality } \\
\text { (postnatal) }\end{array}$ & $\begin{array}{l}\text { Includes postnatal mild/moderate/severe sequelae and } \\
\text { toxoplasmosis-associated infant mortality; excludes termi- } \\
\text { nations and stillbirths }\end{array}$ & All infected live-born children \\
\hline
\end{tabular}

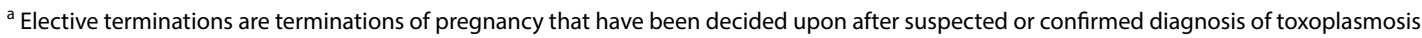


outcomes for each group of interest using the Freeman-Tukey double arcsine method [26, 27]. Randomeffects models took into account both within-study and between-study variability. The alpha value of 0.05 was considered statistically significant. $\mathrm{I}^{2}$ was used to assess heterogeneity. All analyses were performed using $\mathrm{R}$ version 3.0.3 (http://www.r-project.org/) by using R package 'metafor'.

\section{Subgroup/sensitivity analyses}

Subgroup analyses were conducted for each analysis set by trimester, publication date $(<1999$, 19992006, > 2006), and follow-up timepoint. All comparisons were naïve. Findings are presented in Additional file 1: Figs. S13-S76.

Sensitivity analyses were performed on studies that met all of the following criteria: (1) regular screening (e.g., monthly, bimonthly, by trimester, or quarterly); (2) spiramycin dosage between $2-3 \mathrm{~g} /$ day used at any time during the pregnancy; (3) availability of information on transmission rate and/or infant sequelae and its severity; (4) availability of postnatal follow-up data, and (5) studies with $>100$ patients [28]. Several studies were excluded from sensitivity analyses due to the following [29]: in many studies conducted during a certain period (1999-2006) [13, 14, 16], a significant effect of prenatal treatment on the risk of vertical transmission and clinical signs of CT was not detected because very few untreated women were included in their analyses, most untreated women were infected during the third trimester, and severe cases were excluded [30, 31]. Findings are presented in Additional file 1: Figs. S77-S108.

\section{Results}

Out of 300 publications reviewed, 33 studies (32 cohorts and 1 cross-sectional study) comprising a total of 15,406 mothers and 15,250 offspring were eligible for inclusion (Fig. 1). Two studies [23,32] did not report the number of

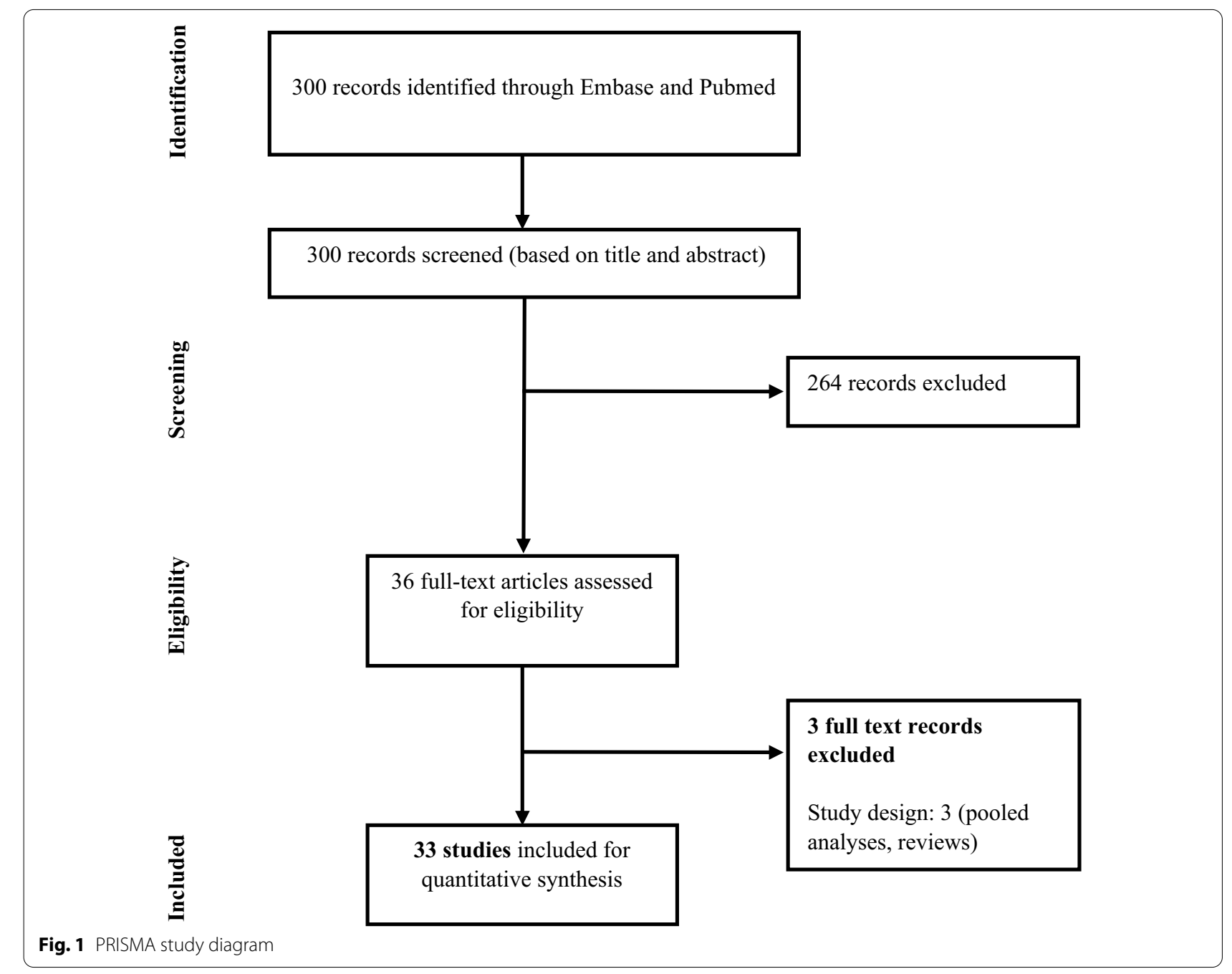


mothers, and the number of offspring was not reported in two studies [33, 34]. Fifteen studies met the criteria for sensitivity analyses (Additional file 1: Table S3). Additional details on study and patient characteristics and the quality assessments are provided in the Additional file 1: Tables S3, S4.

The main analysis was performed by pooling all 33 studies, despite differences across the selected studies with respect to the patient population (country/region, timing of primary infection in gestational stage at which primoinfection incurred), screening/diagnostic methods (with or without regular prenatal screening and polymerase chain reaction [PCR] on amniotic fluid), prenatal treatments (dosage and timing of spiramycin as first treatment, follow-up treatment regimen involving PSF or other), and year of study (1974-2016). Studies were heterogeneous due to the differences in outcome definition, published period, methods of treatment, and medical practices in different countries. Additional file 1: Tables S5, S6 summarize all the results of the meta-analyses.

\section{Mother-to-child transmission}

Twenty studies conducted in 1974-2016 were used to calculate MTCT rates (Fig. 2). The mean rates were $17.6 \%$ (95\% confidence interval [CI] 9.9-26.8\%) for the spiramycin monotherapy group, $19.5 \%$ (95\% CI 14-25.5\%) for the spiramycin and/or PSF group, and 50.7\% (95\% CI $31.2-$ $70 \%)$ for the untreated group $(p<0.001$ for both treated versus untreated comparisons).

\section{Post-transmission outcomes}

Nine studies with up to 1-year follow-up conducted in 1974-2016 were used to calculate rates of infected offspring mortality due to CT but excluding elective terminations of pregnancy due to fetal infection (Additional file 1: Figs. S1, S2). The mean rates were similar in all three groups.

Nine studies with up to 1-year follow-up conducted in 1974-2016 were used to calculate serious/severe sequelae and all offspring mortality rates using the infected mothers as the denominator (Additional file 1: Figs. S3, S4). The mean rates were $1.0 \%$ (95\% CI $0-3.5 \%)$ for the monotherapy group, $1.2 \%$ (95\% CI $0-3.7 \%)$ for spiramycin and/or PSF group, and $21.4 \%$ (95\% CI 2.4-49.7\%) for the untreated group $(p<0.001$ for both treated versus untreated comparisons).

Ten studies with up to 1-year follow-up conducted in 1974-2016 were used to calculate serious/severe sequelae and all offspring mortality rates using the infected fetuses as the denominator (Additional file 1: Figs. S5, S6). The mean rates were 4.7\% (95\% CI $0-22.9 \%)$ for the spiramycin monotherapy group, 7.5\% (95\% CI $1.2-17.5 \%)$ for the spiramycin and/ or PSF group, and 36.5\% (95\% CI 5.1-75.2\%) for the untreated group $(p=0.040$ spiramycin monotherapy versus untreated, $p=0.004$ spiramycin and/or PSF versus untreated).

Twelve studies with up to 1-year follow-up conducted in 1974-2016 were used to calculate mild/moderate/ severe sequelae and postnatal infant mortality rates (Additional file 1: Figs. S7, S8). The mean rates were $32.6 \%$ (95\% CI 16.4-51.1\%) for the monotherapy group, $21.6 \%$ (95\% CI 10-35.6\%) for the spiramycin and/or PSF group, and $65.8 \%$ (95\% CI 27.6-95.9\%) for the untreated group $(p<0.001$ for both treated versus untreated comparisons).

Details on subclinical disease and chorioretinitis are provided in Additional file 1: Figs. S9-S12. From studies published in 1974-2016 with up to 1-year follow-up, the mean rates of subclinical disease in the monotherapy group (63.4\% [95\% CI 43.3-81.3\%], $p=0.003$ ) and in the group treated with spiramycin and/or PSF $(67.5 \%$ [95\% CI 52.9-80.6\%], $p<0.001$ ) were significantly higher than in the untreated group (43.4\% [95\% CI 9.4-81.3\%]). The average rate of chorioretinitis between the untreated group and the group treated only with spiramycin or the group treated with spiramycin and/or PSF were similar.

\section{Subgroup analyses}

MTCT was lower in the spiramycin monotherapy and the spiramycin and/or PSF groups compared to the untreated groups across all trimesters. The rates of all serious/severe sequelae plus mortality tended to be significantly lower in all treated versus untreated groups in both infected pregnant women and in offspring across all publication date periods.

\section{Discussion}

The results of these meta-analyses corroborate previous findings suggesting the benefit of antepartum spiramycin monotherapy or spiramycin and/or PSF in decreasing the rate of MTCT compared to no treatment. A previous meta-analysis using nine studies also found lower rates of MTCT for spiramycin monotherapy or spiramycin and/ or PSF [35]. We present results from a larger evidence base of 33 studies, and report on more clinical posttransmission outcomes such as mortality due to congenital toxoplasmosis, mild/moderate or severe/serious sequelae, and all-cause fetal mortality.

During preliminary searches, we found a meta-analysis published in 2007 that further supported the need for prompt detection and treatment. The systematic review on congenital toxoplasmosis (SYROCOT) compared the effect of earlier versus later prenatal treatment (adjusted for gestational age at seroconversion) and found evidence 
a RE Model $\left(Q=339.68, \mathrm{df}=11, p=0.00 ;\left.\right|^{2}=96.8 \%\right)$ Study

Proportion $[95 \% \mathrm{Cl}]$

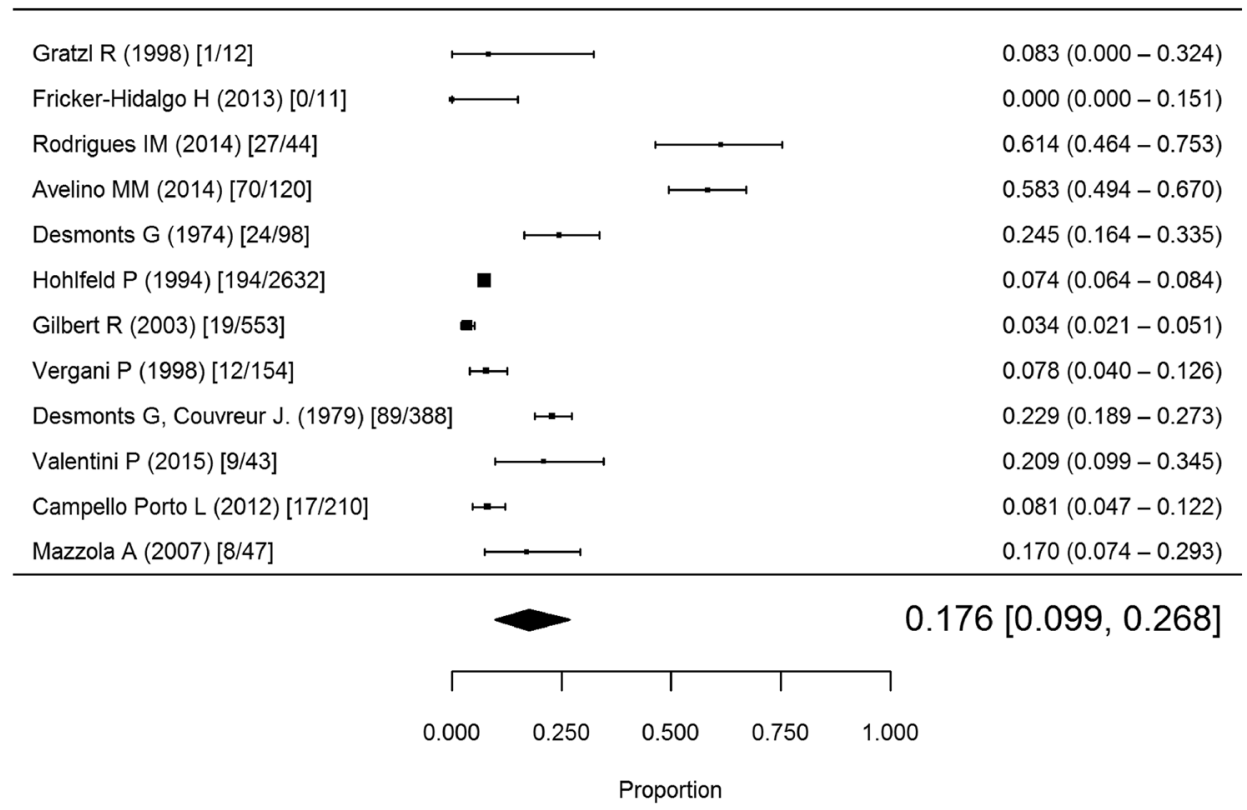

b RE Model $\left(Q=855.68, \mathrm{df}=23, p=0.00 ; \mathrm{l}^{2}=97.3 \%\right)$

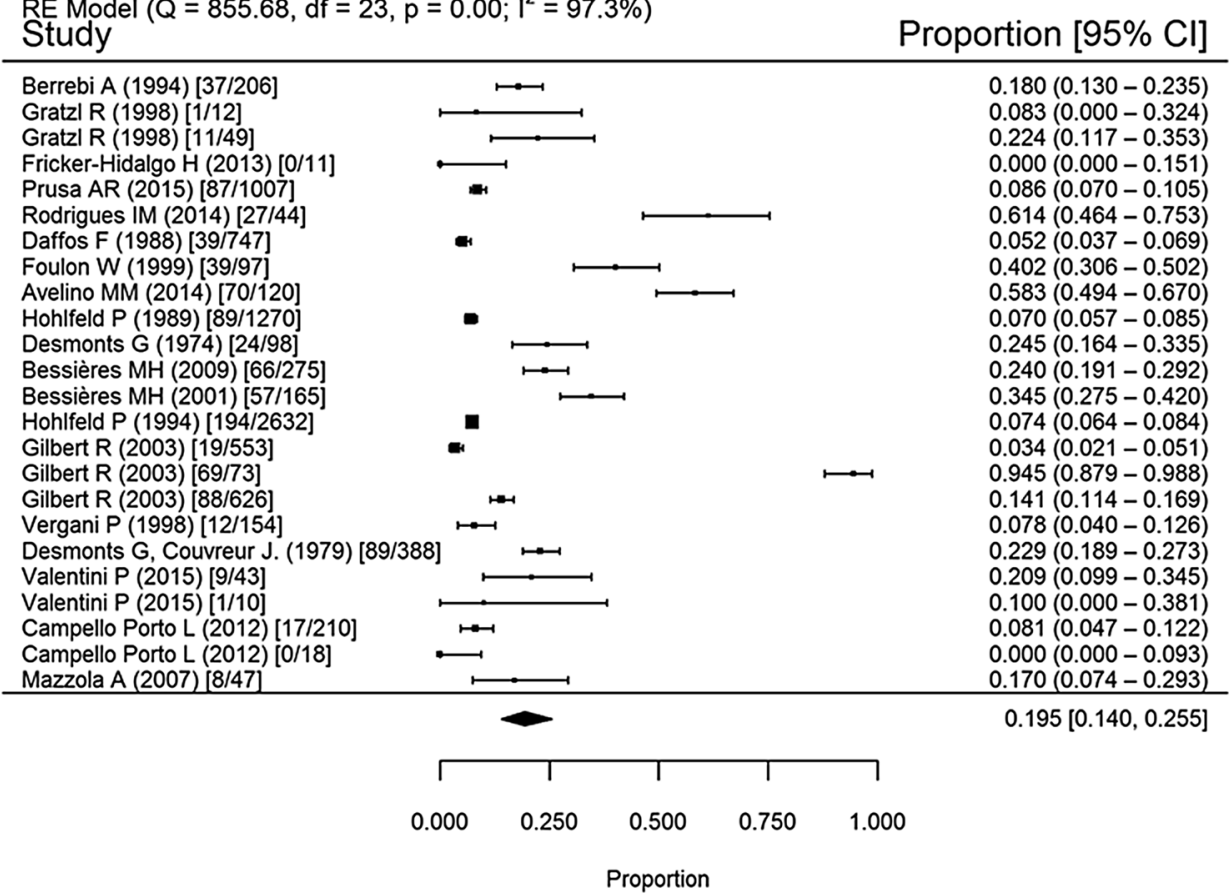

Fig. 2 Forest plot of maternal to child transmission rate by treatment, 1974-2016. a Treatment with spiramycin monotherapy; b treatment with spiramycin and/or PSF treatment; c untreated. Random effects (RE), heterogeneity test $\left(\mathrm{I}^{2}\right.$ ), degrees of freedom (df), confidence interval (CI)

indicating an increased risk of MTCT when prenatal treatment initiation was delayed after maternal seroconversion [18].
Although not included in this review as it was published after the search date, a randomized controlled open-label trial conducted in France (TOXOGEST) 


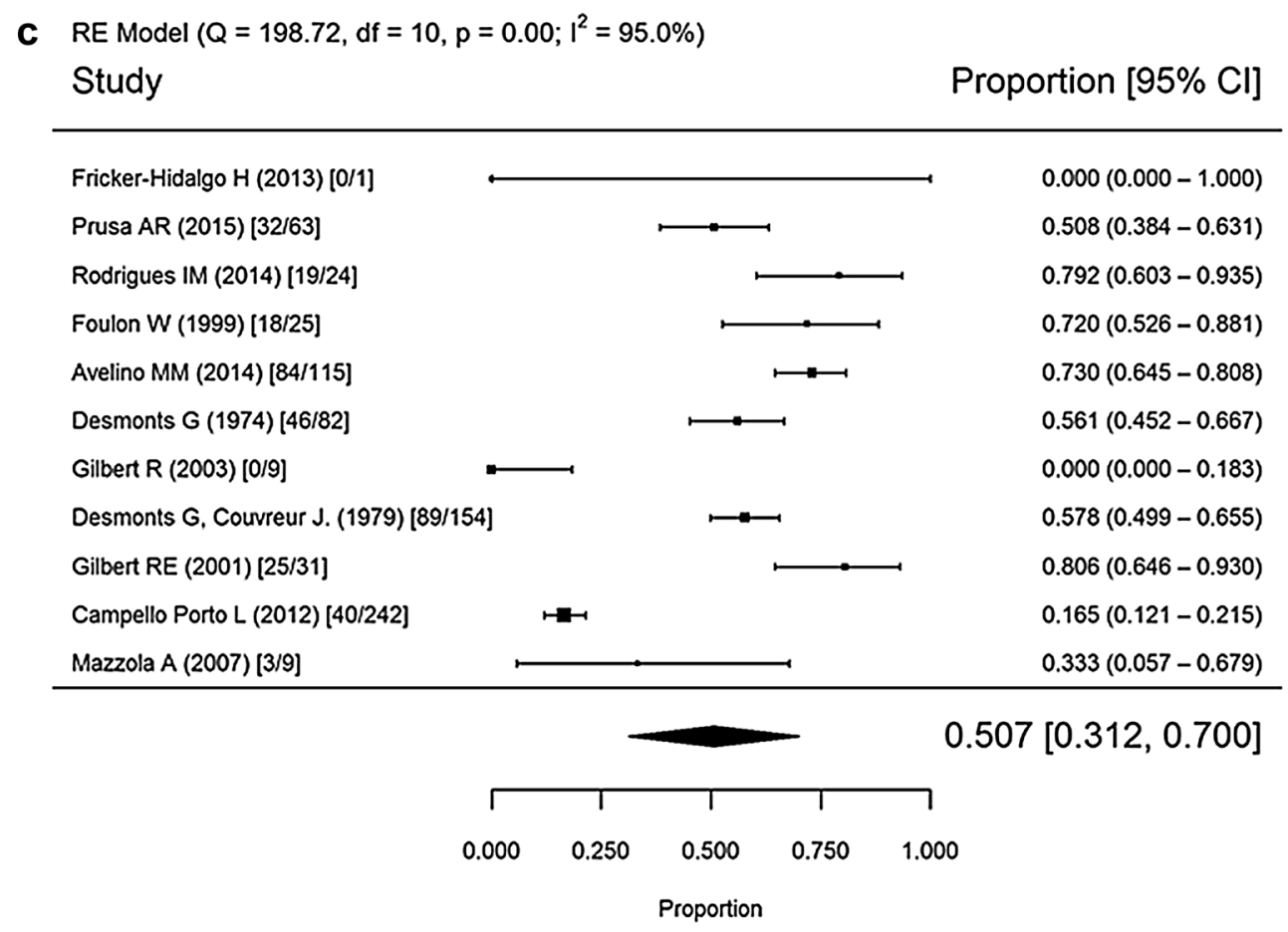

Fig. 2 continued

investigated spiramycin therapy until amniocentesis at 18 weeks, versus initiating pyrimethamine-sulfadiazine-folinic acid as early as 14 weeks to prevent MTCT prior to amniocentesis [36]. Despite the small differences between treatment groups, the results suggest that in the window between 14 and 17 WG, there is an opportunity to reduce the incidence of severe disease in the fetus with use of pyrimethamine-sulfadiazine-folinic acid; however, it is accompanied by a slight increase in risk of severe maternal hypersensitivity. Additional studies might help discriminate the pregnancies that would benefit from earlier diagnosis and initiation of pyrimethamine-sulfadiazine-folinic acid.

In France, TOXOGEST has begun to shift the treatment paradigm towards offering pyrimethamine and sulfadiazine as early as 14 WG. Because of diminished severe neurologic effects in a small number of fetuses treated from 14 to $18 \mathrm{WG}$, this approach has been used for pregnant women who seroconvert in the first trimester and thereafter [36, 37]. Although the approach for treatment after $14 \mathrm{WG}$ is changing, spiramycin remains the standard of care for infections prior to 14 weeks. Other practices offer spiramycin upfront after 14 WG until amniocentesis is performed at 17 to 18 weeks gestation. Since pyrimethamine and sulfadiazine can lead to negative PCR results [22], interpretation of amniocentesis and decisions about subsequent medical care may be complicated when a pregnant woman has received a pyrimethamine sulfadiazine regimen beforehand. While developing new medicines [38-40] may have less teratogenicity in the first trimester than pyrimethamine, and vaccination [41] may be another cost-effective preventative approach, at present gestational screening and spiramycin-based treatment for seroconverting women in the first 14 weeks of gestation protect against congenital toxoplasmosis.

Experiences from many countries have shown that the risk of MTCT and consequential serious/severe sequelae can be decreased with regular screening and prompt antepartum treatment. Austria has for many years utilized an approach, as described above, with favorable outcomes, similar to the current new approach in some clinical practices in France [42]. However, in the U.S., these systems are not generally available, and infected children manifest more severe disease and poorer outcomes [43]. A recent effort has begun to address this unmet need through the development of inexpensive point-of-care testing monthly for pregnant women, and prompt treatment of the pregnant woman [44-46].

Cost-benefit analyses have demonstrated that when costs are constrained to reasonable levels, as in Austria [10] or France, screening and treatment can dramatically improve outcomes and quality of life by improving sight, cognition and motor functions [47-49]. Furthermore, 
the Austrian cost-benefit analysis utilized mathematical modeling to demonstrate that the screening program's benefits were 14 times its cost; food safety education reduced maternal infection; early treatment reduced MTCT rates from 51 to $11 \%$; education, testing, and early treatment reduced cases of CT from 78 to 1 per 10,000; infected children did not have any profound, lifelong injuries and could enter the workforce; and although screening programs cost $€ 1.9$ million per year, the program saved $€ 450$ million over 17 years [10]. In the U.S., mathematical modeling indicated that monthly prenatal screening is cost-saving when tests are $\$ 12$ and congenital infection rates are above $1 / 10,000$ live births [49]. In developing countries with inconsistent prenatal care, the potential spillover benefits of a nationally mandated screening with inexpensive point-of-care tests $(\$ 4-8)$ are extensive as it promotes routine prenatal visits for other health risks [44]. When toxoplasmosis testing is combined with testing for other congenital infections, the potential benefits and cost savings are even larger [50].

In our meta-analyses, no significant difference was found in mortality, excluding elective terminations of pregnancy due to fetal infection. However, rates of MTCT, serious/severe sequelae and mortality combined, and mild/moderate/severe sequelae and infant mortality combined were significantly reduced when mothers received spiramycin monotherapy or spiramycin and/or PSF compared to the untreated group. More studies are required to determine how the trimester at which infection occurred affected the type of adverse outcomes.

\section{Clinical significance}

The findings of this review are an important addition to the current evidence base for antepartum treatment of toxoplasmosis. Some reports published between 1999 and 2006 had raised doubts for some investigators about the effectiveness of spiramycin-containing treatment regimens [13-18]. This led some investigators to advocate for discontinuation of systematic screening and treatment programs for toxoplasmosis $[19,20]$, and others to call for prospective randomized placebo-controlled clinical trials that proved efficacy of treating this infection $[13,18]$. The results of our meta-analyses therefore help address these differences in approach concerning prenatal screening, treatment, and regimens including the use of spiramycin. Additionally, we believe that this review paves the way toward systematic antepartum screening and prompt treatment for patients with T. gondii infection acquired during gestation in parts of the world where this does not yet occur. This facilitates treatment of pregnant women to prevent congenital toxoplasmosis and will allow clinicians to better understand all treatment options at this critical time.
The severity of sequelae tend to increase with infection during earlier stages of pregnancy [51]; however, signs may fail to be captured by studies with insufficient follow-up time [52]. Although only women who are first infected during their pregnancy are thought to be at risk of MTCT, current methods using IgM and IgG cannot differentiate between primary and secondary infection if performed late in pregnancy [53]. Additionally, toxoplasmosis may also present as asymptomatic or flu-like and thus delay testing [53]. Early detection is essential to preventing severe sequelae because $T$. gondii may hide within immune cells and later cause systemic disease [54]. Thus, a wide range of clinical manifestations associated with $\mathrm{CT}$ could be prevented by prompt treatment [54].

Although not evaluated in this study, environmental factors should also be considered when evaluating the antepartum use of spiramycin. In one South American study, more virulent strains of $T$. gondii caused severe infections in $40 \%$ of the infants [55], emphasizing a need for accessible treatment that could be met through spiramycin monotherapy [56]. Cost-effectiveness is particularly important as toxoplasmosis represents a high burden of disease in rural regions, and can be acquired through contaminated soil, water, and meat [57]. Distribution of spiramycin alone, rather than combination therapies, could be more cost-effective where access to medical supplies is limited [56].

This study comes with its limitations. First, it is not as comprehensive as a systematic literature review, and therefore, may not have identified all studies that fulfilled selection criteria. Papers not published in English were excluded, leading to a potential risk of bias and failure to capture spiramycin use in other countries. Studies not yet indexed in databases or published close to the search date were not captured in this paper, which represents a snapshot of an evolving evidence base. In our metaanalyses, we used pooled patients who were untreated throughout pregnancy as historical controls, but the paucity of studies reporting on untreated patients limited sample size. Additionally, not all planned analyses could be performed due to limited data availability, especially for post-transmission outcome endpoints. Prenatal treatment with any drug was preferable to none in reducing MTCT and sequelae. Though treatment with spiramycin was not directly compared to spiramycin and/or PSF via statistical tests, spiramycin monotherapy tended to reduce adverse outcomes at rates similar to the alternative treatment. Significant heterogeneity existed among the studies, due to different $T$. gondii strains, methods of treatment, and potentially the populations' socioeconomic status, which may have influenced the results of the meta-analyses. Moreover, all analyses were naïve with 
no adjustment for gestational age of infection and time to start of treatment. An additional limitation of these meta-analyses is the absence of randomized controlled trials. Nonetheless, the difference in treatment outcomes for mortality and sequelae between spiramycin monotherapy or spiramycin and/or PSF compared to no treatment is robust.

\section{Conclusions}

The results of these meta-analyses support the effectiveness of spiramycin monotherapy and spiramycin and PSF treatments during gestation for the prevention of MTCT of T. gondii and fetal mild-to-severe sequelae. Placebocontrolled randomized clinical trials for this purpose are lacking, but are deemed unethical. Spiramycin should be instituted as soon as possible to any pregnant woman diagnosed with acute infection during the 1st and early 2nd trimester to reduce MTCT, followed by PSF if fetal infection is suspected or confirmed. Since acute T. gondii infection during pregnancy can occur in the absence of symptoms and epidemiologic risk factors, systematic screening is the only approach that would capture all maternal infections and facilitate the early institution of spiramycin and/or PSF during gestation.

\section{Supplementary Information}

The online version contains supplementary material available at https://doi. org/10.1186/s40001-021-00606-7.

Additional file 1. Contains definition of outcomes and denominators; additional details on study characteristics, patient characteristics, and quality assessments; post-transmission outcomes; and all subgroup/sensitivity analyses.

\section{Acknowledgements}

We would like to thank Dr. Fasahath Hussain, Rythme Silva, and Kaylee Anderson for assistance with data acquisition and analysis. We would like to thank Angelica Stamegna and Margaret Lin for general publication assistance. We would like to thank Dr. Todd Feinman and Dr. Michael del Aguila for assistance with critical review. Medical writing was done by Doctor Evidence LLC, and funded by Sanofi. We also gratefully acknowledge the support of National Institute of Allergy and Infectious Diseases R01Al027530 (RMc), the Thrasher Foundation (RMc) and the Mann-Cornwell, Morel, Mussilami, Rooney, Engel, Kehoe, McLeod, Rodriguez, Drago, Quinn, Dunphy, Samuel, Tirado, Taub, Kapnick, Harris, Pritzker, and Van Dusen families (RMc) in foundational work that informed the original analysis although not directly funding this work on this meta-analysis. Lastly, the authors would like to thank the National Collaborative Chicago Based Toxoplasmosis Study (NCCCTS) participants and physician evaluators who have helped develop our understanding of prevention and treatment of toxoplasmosis. We also thank Drs. Eileen Stillwaggon and Larry Sawyer for their insights about prevention of this disease and its costs for care, and benefits of public health impacts of doing so, that also are foundational for this work and application to clinical care.

\section{Authors' contributions}

Conceptualization: AA, JGM, RM, and CZ. Methodology: MSF. Formal analysis: GS. Data curation: SSY. Writing —original draft preparation: MSF and SSY. Writing — review and editing: RM, JGM, and KL. Project administration: ED. All authors were involved in critically revising the manuscript, have provided final approval and take full accountability for the work, for all content and editorial decisions. Authors received no payment from Sanofi directly or indirectly (through a third party) for authorship purposes. All authors read and approved the final manuscript.

Funding

This work was supported by Sanofi.

\section{Availability of data and materials}

All data generated or analyzed during this study are included in this published article and its supplementary information files.

\section{Declarations}

Ethics approval and consent to participate

This study was a literature review and required no ethics approval.

\section{Consent for publication}

Not applicable.

\section{Competing interests}

Elizabeth Drake-Shanahan and Dr. Chengyue Zhu are currently employed by Sanofi. Dr. Akbar Akbary was employed by Sanofi at the time of this analysis but has since retired. Dr. Mir Sohail Fazeli (Evidinno Outcomes Research Inc.), Sophie Yoon, and Gaye Siliman were contracted by Doctor Evidence LLC, which was contracted by Sanofi to conduct the analysis and medical writing Dr. Katherine Laessig is employed by Antios Therapeutics and previously served as a consultant to Sanofi and was compensated for this work. Dr. Rima McLeod prepared a literature review pertinent to use of spiramycin and in accordance with Sunshine laws was compensated for this by Sanofi. Dr. McLeod has studied and published results about a point-of-care test which she and colleagues found meets WHO ASSURED criteria for a perfect screening test [44-46]. This work is currently supported by a grant from The Thrasher Children's Research Charity Foundation and a Research Seed Grant award from The University of Chicago Global Health Center, and is registered in Clinical Trials.gov. She currently is working without compensation with the FDA, with colleagues at LDBio and in Morocco, to introduce this test for use with FDA clearance and CLIA waiver in the USA. She, with colleagues and The University of Chicago, filed a patent application [58] to insure the high quality of this test is sustained. She is working, without compensation, with programs in Morocco [2], Colombia [2], and Panama [manuscripts in preparation] whose physicians and scientists are now, or will, utilize this testing at scale to help pregnant women and their families in these countries to prevent toxoplasmosis [2]. Dr. Montoya was an uncompensated consultant in contributing to the literature review. The remaining authors declare no conflicts of interest.

\section{Author details}

${ }^{1}$ Jack S. Remington Laboratory for Specialty Diagnostics, Palo Alto, CA, USA. ${ }^{2}$ Antios Therapeutics, Mendham, NJ, USA. ${ }^{3}$ Evidinno Outcomes Research Inc, Vancouver, Canada. ${ }^{4}$ Doctor Evidence LLC, Santa Monica, CA, USA. ${ }^{5}$ Department of General Medicines, Sanofi S.A, Bridgewater, NJ, USA. ${ }^{6}$ Division of Biologic Sciences, Departments of Pediatrics (Infectious Diseases) and Ophthalmology and Visual Sciences, University of Chicago, Chicago, IL, USA.

Received: 21 December 2020 Accepted: 14 November 2021

Published online: 11 December 2021

\section{References}

1. McLeod R, Boyer KM, Lee D, Mui E, Wroblewski K, Karrison T, et al. Prematurity and severity are associated with Toxoplasma gondii alleles (NCCCTS, 1981-2009). Clin Infect Dis. 2012;54(11):1595-605.

2. El Bissati K, Levigne P, Lykins J, Adlaoui EB, Barkat A, Berraho A, et al. Global initiative for congenital toxoplasmosis: an observational and international comparative clinical analysis. Emerg Microbes Infect. 2018;7(1):165.

3. Lykins J, Wang K, Wheeler K, Clouser F, Dixon A, El Bissati K, et al. Understanding toxoplasmosis in the united states through "large data" analyses. Clin Infect Dis. 2016;63(4):468-75.

4. Remington JS, McLeod R, Thulliez P, Desmonts G. Toxoplasmosis. In: Remington JS, Klein JO, Wilson CB, Baker CJ, editors. Infectious diseases of 
the fetus and newborn infant. 6th ed. Philadelphia: W.B. Saunders; 2006. p. 947-1091.

5. Montoya JG, Remington JS. Management of Toxoplasma gondii infection during pregnancy. Clin Infect Dis. 2008;47(4):554-66.

6. Albouy R, Duchesnay G, Eloy P, Pestel M, Ravina A, Rey M. A new French antibiotic: spiramycin. Antibiot Annu. 1955;3:223-7.

7. Bogacz J. Comparative effect of various synthetic agents and various antibiotics, including spiramycin, on Toxoplasma. Bull Soc Pathol Exot Filiales. 1954:47(6):903-15.

8. Wigmore RE, Salgueiro FM. Infectious diseases in pregnancy. Medical problems during pregnancy. Berlin: Springer; 2017. p. 77-104.

9. Hotop A, Hlobil H, Gross U. Efficacy of rapid treatment initiation following primary Toxoplasma gondii infection during pregnancy. Clin Infect Dis. 2012;54(11):1545-52.

10. Prusa AR, Kasper DC, Pollak A, Gleiss A, Waldhoer T, Hayde M. The Austrian toxoplasmosis register, 1992-2008. Clin Infect Dis. 2015;60(2):e4-10.

11. Dunn D, Wallon M, Peyron F, Petersen E, Peckham C, Gilbert R. Motherto-child transmission of toxoplasmosis: risk estimates for clinical counselling. Lancet. 1999;353(9167):1829-33.

12. Peyron F, Wallon M, Kieffer F, J.G. G. Toxoplasmosis. In: Wilson CB, Nizet $\checkmark$, Maldonado Y, Remington JS, Klein JO, editors. Infectious Diseases of the Fetus and Newborn Infant (Eighth Edition): W.B. Saunders; 2015. p. 949-1042.

13. Foulon W, Villena I, Stray-Pedersen B, Decoster A, Lappalainen M, Pinon $J M$, et al. Treatment of toxoplasmosis during pregnancy: a multicenter study of impact on fetal transmission and children's sequelae at age 1 year. Am J Obstet Gynecol. 1999;180(2 Pt 1):410-5.

14. Gilbert RE, Gras L, Wallon M, Peyron F, Ades AE, Dunn DT. Effect of prenatal treatment on mother to child transmission of Toxoplasma gondii: retrospective cohort study of 554 mother-child pairs in Lyon, France. Int J Epidemiol. 2001;30(6):1303-8.

15. Gras L, Gilbert RE, Ades AE, Dunn DT. Effect of prenatal treatment on the risk of intracranial and ocular lesions in children with congenital toxoplasmosis. Int J Epidemiol. 2001;30(6):1309-13.

16. Gilbert R, Gras L. Effect of timing and type of treatment on the risk of mother to child transmission of Toxoplasma gondii. BJOG. 2003;110(2):112-20.

17. Gras L, Wallon M, Pollak A, Cortina-Borja M, Evengard B, Hayde M, et al. Association between prenatal treatment and clinical manifestations of congenital toxoplasmosis in infancy: a cohort study in 13 European centres. Acta Paediatr. 2005;94(12):1721-31.

18. Thiébaut R, Leproust $S$, Chêne G, Gilbert R. Effectiveness of prenatal treatment for congenital toxoplasmosis: a meta-analysis of individual patients' data. Lancet. 2007;369(9556):115-22.

19. Boubaker K, Raeber PA, Vaudaux B, Bucher HC, Garweg JG, Hoesli I, et al. Toxoplasmosis during pregnancy and infancy. A new approach for Switzerland. Swiss Med Wkly. 2008;138:1-8.

20. Stricker R, Sitavanc R, Liassine N, de Marval F. Toxoplasmosis during pregnancy and infancy. Swiss Med Wkly. 2009;139(43-44):643-4 (author reply -4).

21. Moher D, Liberati A, Tetzlaff J, Altman DG. Preferred reporting items for systematic reviews and meta-analyses: the PRISMA statement. PLoS Med. 2009;6(7):e1000097.

22. Remington JS, MCLeod R, Wilson CB, Desmonts G. Toxoplasmosis. In: Remington JS, Klein JO, Wilson CB, Nizet V, Maldonado YA, editors. Infectious diseases of the fetus and newborn. 7th ed. Philadelphia:W.B. Saunders; 2011. p. 918-1041.

23. Cortina-Borja M, Tan HK, Wallon M, Paul M, Prusa A, Buffolano W, et al. Prenatal treatment for serious neurological sequelae of congenital toxoplasmosis: an observational prospective cohort study. PLoS Med 2010;7(10):e1000351.

24. Wells GA, Shea B, O'Connell D, Peterson J, Welch V, Losos M, et al. The Newcastle-Ottawa Scale (NOS) for assessing the quality of nonrandomised studies in meta-analyses 2019. http://www.ohri.ca/programs/ clinical_epidemiology/oxford.asp.

25. DerSimonian R, Laird N. Meta-analysis in clinical trials. Control Clin Trials. 1986;7(3):177-88

26. Freeman MF, Tukey JW. Transformations related to the angular and the square root. Ann Math Stat. 1950:607-11.
27. Miller JJ. The inverse of the Freeman-Tukey double arcsine transformation. Am Stat. 1978;32(4):138.

28. Li XL, Wei HX, Zhang H, Peng HJ, Lindsay DS. A meta analysis on risks of adverse pregnancy outcomes in Toxoplasma gondii infection. PloS ONE. 2014;9(5):e97775.

29. Montoya J, Boothroyd J, Kovacs J. Toxoplasma gondii. In: Bennett J, Dolin R, Blaser M, editors. Mandell, Douglas, and Bennett's principles and practice of infectious diseases. 8th ed. Philadelphia: Elsevier; 2015. p. 3122-53.

30. Thulliez P. Commentary: efficacy of prenatal treatment for toxoplasmosis: a possibility that cannot be ruled out. Int J Epidemiol. 2001;30(6):1315-6.

31. Moncada PA, Montoya JG. Toxoplasmosis in the fetus and newborn: an update on prevalence, diagnosis and treatment. Expert Rev Anti Infect Ther. 2012;10(7):815-28.

32. Brézin AP, Thulliez P, Couvreur J, Nobré R, McLeod R, Mets MB. Ophthalmic outcomes after prenatal and postnatal treatment of congenital toxoplasmosis. Am J Ophthalmol. 2003;135(6):779-84.

33. Fricker-Hidalgo H, Cimon B, Chemla C, Darde ML, Delhaes L, L'Ollivier C, et al. Toxoplasma seroconversion with negative or transient immunoglobulin M in pregnant women: myth or reality? A French multicenter retrospective study. J Clin Microbiol. 2013:51(7):2103-11.

34. Wallon M, Franck J, Thulliez P, Huissoud C, Peyron F, Garcia-Meric P, et al. Accuracy of real-time polymerase chain reaction for Toxoplasma gondii in amniotic fluid. Obstet Gynecol. 2010;115(4):727-33.

35. Wei H-X, Wei S-S, Lindsay DS, Peng H-J. A systematic review and metaanalysis of the efficacy of anti-Toxoplasma gondii medicines in humans. PLOS ONE. 2015;10(9):e0138204.

36. Mandelbrot L, Kieffer F, Sitta R, Laurichesse-Delmas H, Winer N, Mesnard L, et al. Prenatal therapy with pyrimethamine + sulfadiazine vs spiramycin to reduce placental transmission of toxoplasmosis: a multicenter, randomized trial. Am J Obstet Gynecol. 2018;219(4):386.

37. Montoya JG. Systematic screening and treatment of toxoplasmosis during pregnancy: is the glass half full or half empty. Am J Obstet Gynecol. 2018:219(4):315-9.

38. McLeod R, Wheeler K, Boyer K. Congenital Toxoplasmosis. In: Read J, editor. Infectious Diseases of the Fetus and Newborn Infant: Harvard; 2018.

39. McLeod R, Cohen W, Dovgin S, Finkelstein L, Boyer KM. Human toxoplasma infection and toxoplasmosis. In: Kim K, Weiss L, editors. Toxoplasma gondii: the model apicomplexan — perspectives and methods. 3rd ed. Cambridge: Academic Press; 2019. p. 117-227.

40. McPhillie M, Zhou Y, Hickman M, Gordon J, Weber CR, Li Q, et al. Potent tetrahydroquinolone eliminates apicomplexan parasites. Front Cell Infect Microbiol. 2020;10:203.

41. El Bissati K, Zhou Y, Paulillo SM, Raman SK, Karch CP, Roberts CW, et al. Protein nanovaccine confers robust immunity against Toxoplasma. NPJ Vaccines. 2017;2(1):1-12.

42. Prusa A-R, Kasper DC, Sawers L, Walter E, Hayde M, Stillwaggon E. Congenital toxoplasmosis in Austria: prenatal screening for prevention is cost-saving. PLoS Negl Trop Dis. 2017;11(7):e0005648.

43. Olariu TR, Remington JS, McLeod R, Alam A, Montoya JG. Severe congenital toxoplasmosis in the United States: clinical and serologic findings in untreated infants. Pediatr Infect Dis J. 2011;30(12):1056-61.

44. Begeman IJ, Lykins J, Zhou Y, Lai BS, Levigne P, El Bissati K, et al. Point-ofcare testing for Toxoplasma gondii IgG/lgM using Toxoplasma ICT IgG-IgM test with sera from the United States and implications for developing countries. PLoS Negl Trop Dis. 2017;1 1(6):e0005670.

45. Lykins J, Li X, Levigne P, Zhou Y, El Bissati K, Clouser F, et al. Rapid, inexpensive, fingerstick, whole-blood, sensitive, specific, point-of-care test for anti-Toxoplasma antibodies. PLoS Negl Trop Dis. 2018;12(8):e0006536.

46. Gomez CA, Budvytyte LN, Press C, Zhou L, McLeod R, Maldonado Y, et al. Evaluation of three point-of-care tests for detection of toxoplasma immunoglobulin IgG and IgM in the United States: proof of concept and challenges. Open Forum Infect Dis. 2018;5(10):215.

47. Peyron F, Mc Leod R, Ajzenberg D, Contopoulos-loannidis D, Kieffer F, Mandelbrot L, et al. Congenital Toxoplasmosis in France and the United States: one parasite, two diverging approaches. PLoS Negl Trop Dis. 2017;11(2):e0005222.

48. McPhillie M, Zhou Y, El Bissati K, Dubey J, Lorenzi H, Capper M, et al. New paradigms for understanding and step changes in treating active and chronic, persistent apicomplexan infections. Sci Rep. 2016;6:29179. 
49. Stillwaggon E, Carrier CS, Sautter M, McLeod R. Maternal serologic screening to prevent congenital toxoplasmosis: a decision-analytic economic model. PLoS Negl Trop Dis. 2011;5(9):e1333.

50. Pomares C, Zhang B, Arulkumar S, Gonfrier G, Marty P, Zhao S, et al. Validation of lgG, IgM multiplex plasmonic gold platform in French clinical cohorts for the serodiagnosis and follow-up of Toxoplasma gondii infection. Diagn Microbiol Infect Dis. 2017:87(3):213-8.

51. McLeod R, Lykins J, Noble AG, Rabiah P, Swisher CN, Heydemann PT, et al. Management of congenital toxoplasmosis. Curr Pediatr Rep. 2014;2(3):166-94.

52. Villena I, Ancelle T, Delmas C, Garcia P, Brezin AP, Thulliez P, et al. Congenital toxoplasmosis in France in 2007: first results from a national surveillance system. Euro Surveill. 2010;15(25):19600.

53. McAuley JB. Congenital Toxoplasmosis. J Pediatric Infect Dis Soc. 2014;3(Suppl 1):S30-5.

54. Khan K, Khan W. Congenital toxoplasmosis: an overview of the neurological and ocular manifestations. Parasitol Int. 2018;67(6):715-21.

55. Avelino MM, Amaral WN, Rodrigues IM, Rassi AR, Gomes MB, Costa TL, et al. Congenital toxoplasmosis and prenatal care state programs. BMC Infect Dis. 2014;14:33.

56. Dubey JP, Lago EG, Gennari SM, Su C, Jones JL. Toxoplasmosis in humans and animals in Brazil: high prevalence, high burden of disease, and epidemiology. Parasitology. 2012;139(11):1375-424.

57. Pappas G, Roussos N, Falagas ME. Toxoplasmosis snapshots: global status of Toxoplasma gondii seroprevalence and implications for pregnancy and congenital toxoplasmosis. Int J Parasitol. 2009;39(12):1385-94.

58. Limonne D, McLeod R, Peyron F, Kamal E-B, Lykins J. Methods and reagents for Toxoplasma infection diagnosis. Google Patents; 2020.

\section{Publisher's Note}

Springer Nature remains neutral with regard to jurisdictional claims in published maps and institutional affiliations.

- fast, convenient online submission

- thorough peer review by experienced researchers in your field

- rapid publication on acceptance

- support for research data, including large and complex data types

- gold Open Access which fosters wider collaboration and increased citations

- maximum visibility for your research: over $100 \mathrm{M}$ website views per year

At BMC, research is always in progress.

Learn more biomedcentral.com/submissions 